\title{
BOOKLET MENSTRUAL HYGIENE DAPAT MENINGKATKAN PENGETAHUAN DAN SIKAP REMAJA
}

\author{
Fauziah Yulfitria' ${ }^{1}$, Shentya Fitriana ${ }^{2}$, Hamidah ${ }^{3}$, Karningsih ${ }^{4}$ \\ 1,2,3,4Jurusan Kebidanan Poltekkes Kemenkes Jakarta III \\ email: zyeajja@gmail.com
}

\begin{abstract}
Background: Menstruation is a natural process that occurs routinely in women every month during the fertile age. Although menstruation occurs routinely, but there are still some teenagers who consider menstruation as sensitive and taboo to tell, they are ashamed to tell it to others, including to his parents (Dasgupta \& Sarkar, 2008). It is one of the causes of lack of adolescent understanding of self-hygiene during menstruation.

Objective: To know the influence of menstrual hygiene booklet on changes in knowledge and attitudes adolescents.

Method: Research the quasi experiment by using research pre-test and post-test group design. With the sample is a part of the student level I Poltekkes Kemenkes Jakarta III academic year 2018-2019 amounting to 84 people. The data used is the primary data by giving the poll to respondents with the analysis of the data Univariat (frequency) and bivariate (Wilcoxon test).

Result: Increased knowledge (75\%) and attitudes (82\%) Respondents after gaining health education using the media booklet $(P=0,000)$.

Conclusion: Booklet can improve the knowledge and attitudes of respondents.

Suggestion: It is expected that young women can practice menstrual hygiene appropriately, and for Health Institutions can use this media booklet in health promotion.
\end{abstract}

Keywords: Booklet menstrual hygiene, knowledge, attitude

\section{ABSTRAK}

Latar Belakang : Menstruasi merupakan proses alamiah yang terjadi secara rutin pada perempuan setiap bulannya selama masa usia subur. Walaupun menstruasi terjadi secara rutin, tetapi masih ada beberapa remaja yang menganggap menstruasi sebagai hal yang sensitive dan tabu untuk diceritakan, sehingga mereka malu untuk menceritakannya kepada orang lain, termasuk kepada orang tuanya (Dasgupta \& Sarkar, 2008). Hal ini menjadi salah satu penyebab kurangnya pemahaman remaja tentang kebersihan diri pada saat menstruasi.

Tujuan : mengetahui pengaruh booklet menstrual hygiene terhadap perubahan pengetahuan dan remaja.

Metode : Penelitian quasi eksperimen dengan menggunakan desain penelitian pre-test dan post-test group design. Dengan sampel adalah sebagian mahasiswa tingkat I Poltekkes Kemenkes Jakarta III Tahun Akademik 2018-2019 yang berjumlah 84 orang. Data yang digunakan adalah data primer dengan memberikan angket kepada responden dengan analisa data secara Univariat (distribusi frekuensi) dan bivariat (uji Wilcoxon).

Hasil : Terdapat peningkatan pengetahuan $(75 \%)$ dan sikap (82\%) responden sesudah mendapatkan Pendidikan kesehatan menggunakan media booklet $(p=0,000)$.

Kesimpulan : Media Booklet dapat meningkatkan pengetahuan dan sikap responden.

Saran : Diharapkan remaja putri dapat mempraktikkan perilaku menstrual hygiene dengan tepat. Dan bagi Institusi Kesehatan dapat menggunakan media booklet ini dalam melakukan promosi Kesehatan.

Kata Kunci : Booklet menstrual hygiene, Pengetahuan, Sikap

\section{PENDAHULUAN}

Menstruasi adalah proses keluarnya darah dari uterus yang terjadi secara periodic dan siklik disertai dengan pelepasan endometrium. Siklus menstruasi normal berkisar 21-35 hari, dengan lama menstruasi tidak lebih dari 15 hari dan jumlah darah yang dikeluarkan 20-80 cc. Menstruasi terjadi akibat penurunan hormone progesterone yang dihasilkan di ovarium. Proses terjadinya menstruasi terdiri dari empat fase, yaitu fase menstruasi, fase ploriferasi, fase sekresi dan fase iskemik (S. Prawiroharjdo, 2011; Potter, Perry, 2010;Chandranita,2009). 
Menstruasi merupakan proses alamiah yang terjadi secara rutin pada perempuan setiap bulannya selama masa usia subur. Walaupun menstruasi terjadi secara rutin, tetapi masih ada beberapa remaja yang menganggap menstruasi sebagai hal yang sensitive dan tabu untuk diceritakan, sehingga mereka malu untuk menceritakannya kepada orang lain, termasuk kepada orang tuanya (Dasgupta \& Sarkar, 2008). Hal ini menjadi salah satu penyebab kurangnya pemahaman remaja tentang kebersihan diri pada saat menstruasi.

Hockenberry \& Wilson (2009) (dalam F. Yulfitria 2018), menyatakan bahwa seseorang harus melakukan perawatan lebih dari biasanya pada saat menstruasi, karena pada saat menstruasi terjadi beberapa perubahan pada tubuhnya. Pada saat menstruasi, hormone prostaglandin mempengaruhi hipotalamus untuk meningkatkan suhu sehingga produksi keringat menjadi meningkat. Selain dari pengaruh hormone prostaglandin, aktivitas fisik yang dilakukan oleh remaja juga dapat meningkatkan produksi keringat. Akibat keringat yang meningkat ini, menyebabkan daerah genitalia eksternal menjadi lebih lembab sehingga dapat meningkatkan risiko pertumbuhan mikroorganisme. Infeksi candida pada daerah vagina merupakan salah satu risiko yang dapat muncul dalam rentan waktu dua minggu atau pada saat menstruasi.

Kebersihan pada saat menstruasi harus disosialisasikan sedini mungkin agar remaja putri terhindar dari penyakit infeksi akibat kebersihan yang tidak terjaga pada saat menstruasi. Perawatan diri pada saat menstruasi dapat berupa pemilihan pembalut yang nyaman, penggantian pembalut sesuai dengan yang dianjurkan, penggunaan celana dalam dari bahan katun dan tidak terlalu ketat, penggunaan air bersih dan teratur membasuh bagian vuvla vagina dengan hati-hati dan benar.

Jika penggunaan pembalut tidak tepat, dapat menyebabkan terjadinya toxic shock syndrome. Pembalut yang dipakai dan tidak diganti dalam waktu lama akan menjadi media berkumpulnya bakteri, dan akan menjadi racun yang dapat masuk kedalam tubuh melalui vagina. Kondisi ini dapat merupakan salah satu faktor predisposisi terjadinya kanker serviks. Karena hal itulah, pengetahuan dan informasi yang adekuat mengenai perawatan diri pada saat menstruasi sangat diperlukan oleh remaja agar terhindar dari berbagai penyakit terutama yang berhubungan dengan organ reproduksi.

Hasil penelitian Wisnuwardhani (1997), melaporkan bahwa $68,7 \%$ responden di Subang dan $77,5 \%$ di Tangerang memiliki status hygiene genital dan menstruasi yang buruk, dan terdapat hubungan yang bermakna antara tingkat pengetahuan tentang menstruasi dengan status hygiene menstruasi. Penelitian S. Lestaringsih (2015), 37,6\% siswi SMPN I Terbanggi Besar Lampung Tengah mempunyai praktik higiene menstruasi yang kurang baik, $41 \%$ pengetahuan responden mengenai hygiene menstruasi kurang baik, faktor pengetahuan ini terbukti berhubungan secara bermakna dengan praktik higiene menstruasi.

\section{METODE PENELITIAN}

Metode penelitian ini adalah quasi eksperimen dengan menggunakan desain penelitian pre-test dan post-test group design. Dalam rancangan ini menggunakan satu kelompok subjek.

Populasi penelitian ini adalah seluruh mahasiswa tingkat I Poltekkes Kemenkes Jakarta III tahun akademik 2019-2020 yang berjumlah 510 orang. Pemilihan mahasiswa tingkat satu menjadi responden karena mereka belum terpapar materi tentang kesehatan reproduksi khususnya mengenai menstrual hygiene.

Sampel penelitian ini adalah sebagian mahasiswa tingkat I Poltekkes Kemenkes Jakarta III tahun akademik 2019-2020 yang berjumlah 84 orang (rumus slovin). Tekhnik pengambilan sampel yang digunakan adalah Stratified Random Sampling, dengan mengambil sampel dari perwakilan tiap Program Studi di Poltekkes Kemenkes Jakarta III secara acak. Waktu penelitian ini dilaksanakan pada bulan Juni - Oktober 2019. Penelitian ini dilakukan di Poltekkes Kemenkes Jakarta III.

Alat pengumpulan data dalam penelitian ini menggunakan kuesioner, yang terdiri dari pertanyaan tentang pengetahuan dan sikap menstrual hygiene. Bentuk pertanyaan adalah pertanyaan tertutup.

Tekhnik pengumpulan data pada penelitian ini adalah dengan memberikan kuesioner untuk memperoleh data primer. Peneliti terlebih dahulu mengajukan izin pengambilan data penelitian ke Direktur Poltekkes Kemenkes Jakarta III, ketua Jurusan di Lingkungan Poltekkes Kemenkes Jakarta III dan Kaprodi di Lingkungan Poltekkes Kemenkes Jakarta III. Setelah mendapat izin, peneliti menemui calon responden untuk memberi penjelasan, setelah responden menyetujui maka dipersilahkan menandatangani lembar persetujuan. Responden yang telah menandatangani lembar persetujuan diberi kuesioner untuk diisi, dan peneliti berada disekitar responden agar bila ada 
pertanyaan dari responden, peneliti dapat langsung menjawab atau menjelaskan. Responden diingatkan bahwa semua pertanyaan yang ada harus diisi dan setelah selesai dikembalikan kepada peneliti langsung. Setelah responden mengisi kuesioner, responden akan mendapatkan booklet yang berisikan informasi tentang menstrual hygiene. Dua bulan kemudian, responden akan diberikan kuesioner yang sama, guna menilai pengetahuan dan sikap responden yang berhubungan dengan menstrual hygiene.

Untuk dapat menjawab tujuan yang ingin dicapai dalam penelitian ini, maka dilakukan 2 teknik analisa yaitu Analisa Univariat (distribusi frekuensi variabel independen atau dependen) dan Analisa Bivariat (Wilcoxon Test).

\section{HASIL}

Analisa Univariat

Tabel 1.

Usia dan Usia Menars Responden

\begin{tabular}{llcc}
\hline Karakteristik & Variabel & $\mathrm{F}$ & $\%$ \\
\hline Usia & $>17$ Tahun & 70 & 83,3 \\
& $\leq 17$ Tahun & 14 & 16,7 \\
Usia Menars & $>12$ Tahun & 42 & 50 \\
& $\leq 12$ Tahun & 42 & 50 \\
\hline \multicolumn{2}{c}{ Jumlah } & 84 & 100 \\
\hline
\end{tabular}

Berdasarkan tabel diatas, diketahui $83,3 \%$ (70) responden berusia >17 Tahun dan $50 \%$ (42) responden mengalami menarche pada usia $\leq 12$ Tahun.

Tabel 2.

Gambaran Skor Pengetahuan Responden Sebelum dan Sesudah Mendapatkan Pendidikan Kesehatan Melalui Media Booklet

\begin{tabular}{lcccc}
\hline $\begin{array}{c}\text { Skor } \\
\text { Pengetahuan }\end{array}$ & Mean & SD & $\begin{array}{c}\text { Min - } \\
\text { Maks }\end{array}$ & $95 \% \mathrm{Cl}$ \\
\hline Sebelum & 9,39 & 1,693 & $5-13$ & $9,03-9,76$ \\
Sesudah & 11,02 & 1,976 & $6-15$ & $10,60-11,45$ \\
\hline
\end{tabular}

Berdasarkan tabel diatas, diketahui rata-rata pengetahuan responden sebelum mendapatkan Pendidikan kesehatan melalui media booklet adalah 9,39 (95\% Cl 9,03-9,76) dengan standar deviasi 1,693. Skor pengetahuan paling rendah adalah 5 dan skor pengetahuan paling tinggi adalah 13. Dari hasil estimasi interval dapat disimpulkan bahwa 95\% diyakini bahwa rata-rata skor pengetahuan responden sebelum mendapatkan Pendidikan kesehatan melalui media booklet berada diantara 9,03 sampai dengan 9,76 . Kemudian setelah mendapatkan Pendidikan kesehatan melalui media booklet rata-rata skor pengetahuan responden mengalami peningkatan yaitu $11,02(95 \% \mathrm{Cl} 10,60$ $11,45)$ dengan standar deviasi 1,976. Skor pengetahuan setelah mendapatkan Pendidikan kesehatan melalui media booklet paling rendah menjadi 6 dan skor tertinggi 15, serta dengan 95\% $\mathrm{Cl}$ diketahui bahwa rata-rata skor pengetahuan setelah mendapatkan Pendidikan kesehatan melalui media booklet berada diantara 10,60 sampai dengan 11,45 .

Tabel 3.

Gambaran Skor Sikap Responden Sebelum dan Sesudah Mendapatkan Pendidikan Kesehatan Melalui Media Booklet

\begin{tabular}{ccccc}
\hline $\begin{array}{c}\text { Skor } \\
\text { Sikap }\end{array}$ & Mean & SD & $\begin{array}{c}\text { Min - } \\
\text { Maks }\end{array}$ & $95 \% \mathrm{Cl}$ \\
\hline Sebelum & 47,45 & 2,906 & $41-53$ & $46,82-48,08$ \\
Sesudah & 50,18 & 3,070 & $43-57$ & $49,51-50,84$ \\
\hline
\end{tabular}

Berdasarkan tabel diatas, diketahui rata-rata sikap responden sebelum mendapatkan Pendidikan kesehatan melalui media booklet adalah 47,45 $(95 \% \mathrm{Cl} 46,82-48,08)$ dengan standar deviasi 2,906. Skor sikap paling rendah adalah 41 dan skor sikap paling tinggi adalah 53. Dari hasil estimasi interval dapat disimpulkan bahwa 95\% diyakini bahwa rata-rata skor sikap responden sebelum mendapatkan Pendidikan kesehatan melalui media booklet berada diantara 46,82 sampai dengan 48,08. Kemudian setelah mendapatkan Pendidikan kesehatan melalui media booklet rata-rata skor sikap responden mengalami peningkatan yaitu 50,18 (95\% Cl 49,51-50,84) dengan standar deviasi 3.070. Skor sikap setelah mendapatkan Pendidikan kesehatan melalui media booklet paling rendah menjadi 43 dan skor tertinggi 57 , serta dengan $95 \%$ $\mathrm{Cl}$ diketahui bahwa rata-rata skor sikap setelah mendapatkan Pendidikan kesehatan melalui media booklet berada diantara 49,51 sampai dengan 50,84 .

\section{Analisa Bivariat}

Uji Normalitas Data

Untuk menentukan uji statistik selanjutnya peneliti akan melakukan uji normalitas data terlebih dahulu menggunakan Uji Kologorov Smirnov dengan hasil sebagai berikut.

Dari tabel dibawah diketahui data dari seluruh variabel menunjukan mayoritas data tidak berdistribusi normal, hanya data sikap sebelum mendapatkan Pendidikan kesehatan melalui media booklet yang berdistribusi normal. Maka uji statistik 
yang digunakan adalah uji statistik non parametrik yaitu uji Wilcoxon.

Tabel 4.

Uji Normalitas Data

\begin{tabular}{ccc}
\hline Kategori & $p$ Value & Keterangan \\
\hline Pengetahuan sebelum & 0,000 & Tidak normal \\
Pengetahuan sesudah & 0,000 & Tidak normal \\
Sikap sebelum & 0,200 & Normal \\
Sikap sesudah & 0,022 & Tidak normal \\
\hline
\end{tabular}

Pengaruh Pendidikan Kesehatan Melalui Media Booklet Terhadap Pengetahuan.

Tabel 5.

Skor Pengetahuan Responden

\begin{tabular}{lcccc}
\hline Pengetahuan & N & $\begin{array}{c}\text { Mean } \\
\text { Rank }\end{array}$ & $\begin{array}{c}\text { Sum of } \\
\text { Rank }\end{array}$ & $\begin{array}{c}p \\
\text { Value }\end{array}$ \\
\hline Negative Ranks & 6 & 21,33 & 128,00 & 0,000 \\
Positif Ranks & 63 & 36,30 & 2287,00 & \\
Ties & 15 & & & \\
\hline Total & 84 & & & \\
\hline
\end{tabular}

Dari tabel di atas diketahui nilai negatif rank sebesar 6 yang menunjukan adanya selisih (negatif) antara skor pengetahuan sebelum dan sesudah mendapatkan Pendidikan kesehatan melalui media booklet. Artinya disini terdapat 6 responden yang mengalami penurunan skor pengetahuan setelah mendapatkan Pendidikan kesehatan melalui media booklet. Selain itu diketahui nilai positif rank sebesar 63 yang menunjukan adanya selisih (positif) antara skor pengetahuan sebelum dan sesudah mendapatkan Pendidikan kesehatan melalui media booklet. Artinya disini terdapat 63 responden yang mengalami peningkatan skor pengetahuan setelah mendapatkan Pendidikan kesehatan melalui media booklet. Kemudian diketahui nilai ties sebesar 15 yang menunjukan ada 15 responden yang skor pengetahuannya sama atau tidak mengalami perubahan skor pengetahuan dari sebelum dan sesudah mendapatkan Pendidikan kesehatan melalui media booklet. Dari hasil uji statistik didapatkan $P$ Value 0,000 yang menunjukan adanya pengaruh yang signifikan Pendidikan kesehatan melalui media booklet terhadap pengetahuan responden.

Pengaruh Pendidikan Kesehatan Melalui Media Booklet Terhadap Sikap

Dari tabel di bawah diketahui nilai negatif rank sebesar 4 yang menunjukan adanya selisih (negatif) antara skor sikap sebelum dan sesudah mendapatkan Pendidikan kesehatan melalui media booklet. Artinya disini terdapat 4 responden yang mengalami penurunan skor sikap setelah mendapatkan Pendidikan kesehatan melalui media booklet. Selain itu diketahui nilai positif rank sebesar 69 yang menunjukan adanya selisih (positif) antara skor sikap sebelum dan sesudah mendapatkan Pendidikan kesehatan melalui media booklet. Artinya disini terdapat 69 responden yang mengalami peningkatan skor sikap setelah mendapatkan Pendidikan kesehatan melalui media booklet. Kemudian diketahui nilai ties sebesar 11 yang menunjukan ada 11 responden yang skor sikapnya sama atau tidak mengalami perubahan skor sikap dari sebelum dan sesudah mendapatkan Pendidikan kesehatan melalui media booklet. Dari hasil uji statistik didapatkan $P$ Value 0,000 yang menunjukan adanya pengaruh yang signifikan Pendidikan kesehatan melalui media booklet terhadap sikap responden.

Tabel 6.

Skor Sikap Responden

\begin{tabular}{lcccc}
\hline \multicolumn{1}{c}{ Sikap } & N & $\begin{array}{c}\text { Mean } \\
\text { Rank }\end{array}$ & $\begin{array}{c}\text { Sum of } \\
\text { Rank }\end{array}$ & $\begin{array}{c}p \\
\text { Value }\end{array}$ \\
\hline Negative Ranks & 4 & 10,75 & 43,00 & \\
Positif Ranks & 69 & 38,52 & 2658,00 & 0,000 \\
Ties & 11 & & & \\
\hline Total & 84 & & & \\
\hline
\end{tabular}

\section{PEMBAHASAN}

\section{Usia dan Usia Menarche Responden}

Hasil penelitian ini menunjukkan mayoritas responden berumur $>17$ tahun yaitu sebanyak 70 orang $(83,3 \%)$. Hal ini menunjukkan bahwa respoden tergolong remaja. Masa remaja adalah masa transisi antara masa kanak-kanak kemasa dewasa, dan merupakan masa pencarian identitas diri. Selain itu pada masa remaja, mereka mengalami pertumbuhan fisik dan psikis yang sangat pesat, termasuk pertumbuhan alat reproduksinya. Mereka harus mendapatkan informasi yang baik mengenai pemeliharaan kesehatan reproduksi dan apabila mereka tidak mendapatkan informasi maka kemungkinan akan menimbulkan masalah pada kesehatan reproduksinya.

Usia menarche responden pada usia $\leq 12$ tahun yaitu sebanyak 42 orang $(50 \%)$. Menarche adalah menstruasi yang pertama kali datang dan merupakan sebagai pertanda kematangan seksual pada remaja wanita. Pada saat ini, wanita tersebut diharapkan dapat melakukan perawatan yang benar dan tepat pada alat reproduksinya, sehingga tidak terjadi gangguan pada alat reproduksinya. $\mathrm{H}$ 
Wiknjosastro (2005) berpendapat, bahwa menarche pada masa remaja terjadi pada usia 11-13 tahun. Usia menarche pada remaja berpengaruh pada perilaku terkait menstruasi. Remaja yang mengalami menarche pada masa remaja awal, akan mengalami hygiene menstruasi yang kurang baik. Karena pada saat itu pengetahuan nya masih kurang tentang hygiene menstruasi. Jika mereka mangalami menstruasi pada remaja tengah atau akhir, maka memungkinkan mereka sudah mendapatkan informasi mengenai hygiene menstruasi sehingga perilaku hygiene menstruasinya menjadi lebih baik ( $F$ Yulfitria, 2018).

\section{Pengaruh Pendidikan Kesehatan Melalui Media Booklet Terhadap Pengetahuan.}

Dari hasil Analisa data terlihat rata-rata skor pengetahuan sebelum mendapatkan Pendidikan kesehatan melalui media booklet dan setelah mendapatkan Pendidikan kesehatan melalui media booklet mengalami peningkatan dari skor 9,39 menjadi 11,02 . Hasil analisis bivariate dapat dilihat nilai positif rank sebesar 63 yang berarti terdapat $63(75 \%)$ responden dari 84 responden yang mengalami peningkatan pengetahuan. Dari hasil uji wilcoxon didapatkan $P$ Value 0,000 yang menunjukan bahwa Pendidikan kesehatan menggunakan media booklet dapat meningkatkan pengetahuan responden.

Peningkatan pengetahuan dapat dipengaruhi oleh beberapa factor, seperti Pendidikan, pengalaman pribadi atau dari orang lain, lingkungan dan media massa (Notoadmojo, 2012). Pemanfaatan media dalam memberikan Pendidikan kesehatan bertujuan untuk menarik perhatian seseorang terhadap suatu masalah atau terhadap informasi yang akan diberikan, sehingga dapat meningkatkan pengetahuan dan sikap seseorang (Machfoed I, 2005).

Dari hasil penelitian ini, peningkatan pengetahuan dipengaruhi oleh pemberian Pendidikan kesehatan dengan menggunakan media booklet. Walaupun memiliki keterbatasan, media booklet juga memiliki beberapa kelebihan, seperti informasi yang terkandung di media booklet dapat dipelajari secara mandiri karena setiap responden diberikan media booklet untuk dibawa pulang sehingga dapat dipelajari setiap saat, sehingga terjadi proses belajar didalamnya (Aini, 2010). Proses belajar dipengaruhi oleh 4 faktor utama, yaitu materi, lingkungan, instrumental dan faktor individual (Notoadmojo, 2012).

Penelitian ini sejalan dengan penelitian Zulaekah (2012) yang mengemukakan bahwa media booklet dapat meningkatkan pengetahuan dengan nilai $p=0,0001$. Dan hampir sama dengan hasil penelitian Aini (2010) yang menyatakan bahwa intervensi booklet berpengaruh terhadap pengetahuan remaja $(p=0,002)$. Penggunaan media dalam memberikan informasi akan memberikan hasil yang positif pada outputnya.

Penggunaan Pendidikan kesehatan dengan menggunakan media booklet dapat meningkatkan pengetahuan responden karena materi yang diberikan dapat menarik perhatian responden sehingga akan menimbulkan minat untuk mempelajarinya. Alat bantu atau media Pendidikan kesehatan dapat membantu seseorang dalam menerima informasi sesuai dengan kemampuan penangkapan panca indra. Semakin banyak indra yang digunakan, naka semakin baik penerimaan seseorang terhadap pesan atau materi yang disampaikan (U Suliha, 2002). Booklet adalah salah satu media Pendidikan kesehatan yang berguna untuk menyampaikan pesan-pesan kesehatan dalam bentuk buku, yang terdiri dari tulisan dan gambar. Setelah diberikan informasi tentang menstrual hygiene dengan menggunakan media booklet, terbukti terjadi peningkatan pengetahuan responden.

\section{Pengaruh Pendidikan Kesehatan Melalui Media Booklet Terhadap Sikap}

Dari analisis univariat terlihat rata-rata skor sikap sebelum mendapatkan Pendidikan kesehatan melalui media booklet dan setelah mendapatkan Pendidikan kesehatan melalui media booklet mengalami peningkatan dari skor 47,45 menjadi 50,18 . Hasil analisis bivariate dapat dilihat nilai positif rank sebesar 69 yang berarti terdapat 69 $(82 \%)$ responden dari 84 responden yang mengalami peningkatan sikap. Dari hasil uji wilcoxon didapatkan $P$ Value 0,000 yang menunjukan bahwa Pendidikan kesehatan menggunakan media booklet dapat meningkatkan sikap responden.

Setelah seseorang mengetahui suatu pengetahuan atau objek atau stimulus, proses selanjutnya adalah bersikap terhadap pengetahuan atau objek atau stimulus tersebut. Sikap seseorang meliputi 3 komponen, yaitu komponen kognitif, komponen afektif dan komponen konitif. Komponen kognitif berhubungan dengan kepercayaan seseorang mengenai apa yang berlaku atau apa yang benar bagi objek sikap. Jika kepercayaan telah terbentuk, maka akan menjadi dasar seseorang mengenai apa yang diharapkan dari objek tertentu. Komponen afektif menyangkut masalah emosional seseorang terhadap objek sikap, atau perasaan yang dimiliki objek tertentu. 
Komponen konatif menunjukkan bagaimana perilaku atau kecenderungan berperilaku dengan yang ada dalam diri seseorang berkaitan dengan objek sikap yang dihadapi (Notoadmojo, 2012).

Pada setiap orang, sikap akan terbentuk setelah terjadi proses tahu terlebih dahulu. Informasi yang didapatkan melalui media dapat membawa pesan sugestif sehingga menjadi dasar dalam membentuk sikap tertentu. (Azwar 2005). Faktor lain yang dapat mempengaruhi sikap seseorang adalah pengalaman pribadi, pengaruh orang lain yang dianggap penting, pengaruh budaya, Lembaga Pendidikan dan faktor emosional.

Hasil penelitian ini mendukung penelitian sebelumnya yang menyatakan bahwa Pendidikan kesehatan memberikan pengaruh yang positif terhadap peningkatan sikap responden tentang kanker serviks dan skrining kanker serviks (ChinweEr, 2015, dalam F Yulfitria 2017). Pendidikan kesehatan adalah kombinasi dari pengalaman belajar yang dirancang dengan menggunakan beberapa metode yang bertujuan untuk mengubah sikap individu dengan cara meningkatkan pemahaman mereka tentang informasi tersebut. Metode yang digunakan dalam memberikan informasi dapat merangsang sikap yang positif dalam upaya meningkatkan kesehatan. Responden yang mendapatkan informasi melalui media booklet dapat membawa pulang media tersebut sehingga mereka memiliki kesempatan untuk membacanya kembali di rumah.

Media Booklet dapat mempengaruhi pengetahuan dan sikap responden karena media booklet memiliki beberapa keunggulan, seperti : tampilannya menarik, terdapat gambar, menggunakan Bahasa yang sederhana yang mudah dimengerti dan responden dapat mempelajarinya secara mandiri karena mereka diberikan media booklet untuk dibawa pulang sehingga dapat dipelajari setiap saat.

\section{KESIMPULAN}

Terdapat peningkatan pengetahuan $(75 \%)$ dan sikap (82\%) responden sebelum dan sesudah mendapatkan Pendidikan kesehatan menggunakan media booklet $(p=0,000)$.

\section{SARAN}

Dari hasil penelitian ini, diharapkan remaja putri dapat mempraktikkan perilaku menstrual hygiene dengan tepat dan perlunya evaluasi lanjutan untuk melihat apakah remaja putri mampu mempraktikkan menstrual hygiene secara terus menerus. Bagi Institusi Kesehatan diharapkan dapat menggunakan media booklet ini untuk melakukan promosi kesehatan dalam upaya meningkatkan pengetahuan, sikap dan perilaku remaja mengenai menstrual hygiene. Dan bagi peneliti selanjutnya dapat mengembangkan penelitian ini dan mengkaji lebih dalam mengenai menstrual hygiene

\section{DAFTAR PUSTAKA}

Aini, F. (2010). Pengaruh Pendidikan Kesehatan Reproduksi Remaja Melalui Media Booklet Terhadap Perubahan Pengetahuan dan Sikap Santri tentang Kesehatan Reproduksi di Pesantren Darul Hikmah dan Pesantren Ta'dib Al-Syakirin di Kota Medan Tahun 2010.

Azwar, S. (2007). Sikap Manusia Teori dan Pengukurannya, Edisi ke-2. Yogyakarta: Pustaka Pelajar Offset.

Chandranita, I. A. (2009). Memahami kesehatan reproduksi wanita. Jakarta: EGC.

Dasgupta, A., \& Sarkar, M. (2008). Menstrual hygiene: how hygienic is the adolescent girl?. Indian journal of community medicine: official publication of Indian Association of Preventive \& Social Medicine, 33(2), 77.

Dhingra, R., Kumar, A., \& Kour, M. (2009). Knowledge and practices related to menstruation among tribal (Gujjar) adolescent girls. Studies on Ethno-Medicine, 3(1), 43-48.

F Yulfitria 2017. Pengaruh Pendidikan Kesehatan dalam Meningkatkan Pengetahuan tentang Pencegahan Keputihan Patologi. Jurnal Bidan. Jakarta

F Yulfitria (2018). Faktor-Faktor Yang Berhubungan Dengan Perilaku Menstrual Hygiene Pada Mahasiswa Jurusan Kebidanan Poltekkes Kemenkes Jakarta III

Notoatmodjo, S. (2012). Promosi kesehatan dan perilaku kesehatan. Jakarta: rineka cipta, 4562.

Potter, P., \& Perry, A. (2010). Fundamental Of Nursing: Consep, Proses and Practice (7. Vol. 3). Jakarta: EGC.

S. Lestariningsih (2015). Faktor-faktor yang Berhubungan dengan Praktik Higiene Menstruasi. Jurnal Kesehatan metro Sai Wawai Volume VIII No 2. Lampung

S. Prawirohardjo. 2011. Ilmu Kandungan. PT Bina Pustaka Sarwono Prawirohardjo. Jakarta

U Suliha, 2002, Pendidikan Kesehatan Dalam Keperawatan, EGC. Jakarta.

H Wiknjosastro, 2005. IImu Kandungan. Yayasan Bina Pustaka Sarwono Prawirohardjo. Jakarta. 
Wisnuwardhani, S. D., \& Agustina, F. M. T. (1997). Studi Higienis Menstruasi dan Infeksi Alat Reproduksi. Bagian Kebidanan dan Kandungan FK dan Kelompok Studi Kesehatan Reproduksi FKM UI. Jakarta.
Zulaekah, S. (2012). Pendidikan gizi dengan media booklet terhadap pengetahuan gizi. KEMAS: Jurnal Kesehatan Masyarakat, 7(2), 127133. 